\title{
Mahkota teleskopik sebagai retainer alternatif gigitiruan lepasan Telescopic crown as alternative retainer of removable denture
}

\author{
${ }^{1}$ Sri W. Rais, ${ }^{2}$ Setyawan Bonifacius \\ Program Studi Pendidikan Dokter Gigi Universitas Sriwijaya, Palembang \\ Bagian Prostodonsia, Fakultas Kedokteran Gigi Universitas Padjajaran, Bandung \\ Indonesia
}

\begin{abstract}
In making removable denture, some aspects must be considered: retention, stabilization, support, comfort, and aesthetic. Retention plays an important role in the success of a removable denture. Retention can be obtained from the undercut area, or friction of the denture's components to the abutment or abutment. Clasp as a retainer, both of metal casting and wire have been frequently used in the removable partial denture. The clasp has some shortcomings in its using, namely color of the metal can sometimes interfere with the aesthetic of the wearer and cannot be placed on teeth that have experienced extensive caries. Telescopic crown as retainer has several advantages, which can be used on crown of abutment that has experienced extensive caries or tooth that will be an abutment but have endodontic-treated. On telescopic crowns, retention is obtained from the friction between the primary crowns against secondary crown that serves as a retainer. This case report describes two cases of a removable denture with a metal framework using a telescopic crown on one tooth that serves as a retainer in the case of one-side free-end edentulous.
\end{abstract}

Keywords: removable denture, retainer, friction, telescopic crown

\begin{abstract}
ABSTRAK
Pada pembuatan gigitiruan lepasan, hal yang harus diperhatikan antara lain retensi, stabilisasi, dukungan, kenyamanan, dan estetik. Retensi memegang peranan penting dalam hal keberhasilan suatu gigitiruan lepasan. Retensi dapat diperoleh antara lain dari daerah undercut, ataupun friksi dari komponen-komponen gigitiruan terhadap gigi penyangga ataupun jaringan pendukung. Retainer berupa cengkeram, baik dari bahan logam tuang maupun kawat sudah sering digunakan dalam pembuatan gigitiruan sebagian lepasan. Cengkeram mempunyai beberapa kekurangan dalam penggunaanya. Kekurangan tersebut adalah warna logam dari cengkeram tersebut dapat mengganggu estetik pemakainya serta terkadang tidak dapat ditempatkan pada gigi yang sudah mengalami karies luas. Retainer mahkota teleskopik mempunyai beberapa kelebihan, diantaranya dapat digunakan pada gigi penyangga dengan mahkota klinis yang sudah mengalami karies yang luas atau gigi yang akan dijadikan penyangga sudah dilakukan perawatan endodontik. Pada mahkota teleskopik, retensi diperoleh dari friksi antara mahkota primer terhadap mahkota sekunder yang berfungsi sebagai retainer. Pada laporan kasus ini dipaparkan dua kasus pembuatan gigitiruan lepasan rangka logam dengan menggunakan mahkota teleskopik pada salah satu giginya yang berfungsi sebagai retainer pada kasus edentulus berujung bebas salah satu sisinya.
\end{abstract}

Kata kunci: gigitiruan lepasan, retainer, friksi, mahkota teleskopik

Koresponden: Sri W. Rais, Program Studi Pendidikan Dokter Gigi Universitas Sriwijaya, Palembang, Indonesia. Email:sri_wrais@yahoo.co.id

\section{PENDAHULUAN}

Pada perkembangan zaman yang modern ini, perawatan gigi memungkinkan seorang dokter gigi melakukan restorasi dan berusaha mempertahankan gigi secara alami untuk kepentingan sebagai gigi penyangga. Secara konvensional, tooth-supported denture meliputigigitiruan jembatan cekat,kombinasi cekat dan gigitiruan lepasan, gigitiruan sebagian lepasan serta overdenture.

Setiap gigitiruan yang dipasang di dalam mulut mempunyai risiko merusak kesehatan gigi beserta jaringanpendukungnya.Kerusakan jaringan tersebut dapat diperkecil dengan membuat desain gigitiruan secara tepat dan menginstruksikan kepada pasien untuk menjaga kebersihan mulut dan gigitiruannya. ${ }^{1}$

Pada pembuatan gigitiruan lepasan, beberapa aspek yang harus diperhatikan, antara lain retensi, stabilitas, dukungan, kenyamanan dan estetik. Retensi memegang peranan penting dalam hal keberhasilan suatu gigitiruan lepasan. Retensi dapat diperoleh antara lain dari daerah undercut ataupun friksional dari komponen-komponen gigitiruan terhadap gigi penyangga ataupun jaringan pendukung.

Pemakaian gigitiruan bertujuan bukan hanya memperbaiki fungsi pengunyahan, fungsi fonetik, danfungsi estetik, tetapi juga harus mempertahankan kesehatan jaringan sisa. Untuk tujuan terakhir ini selain erat kaitannya dengan pemeliharaan kebesihan mulut, juga bagaimana mengatur gaya-gaya yang terjadi masih bersifat fungsional atau mengurangi besarnya gaya yang kemungkinan akan merusak. ${ }^{1}$

Besar dan arah pergerakan gigitiruan sebagian lepasan selama berfungsi dipengaruhi oleh struktur pendukungnya yang alami dan disain gigitiruannya. 
Gaya-gaya fungsional akan didistribusikan ke gigi pendukung melalui dudukan oklusalnya, guiding plane, dan directretainer.Lokasi dan disain sandaran oklusal,lengan cengkeram, dan posisi konektor minor dalam hubungannya dengan guiding plane adalah kunci dalam mengontrol distribusi beban ke gigi sandaran. Dengan demikian desain yang optimal dapat memelihara kesehatan gigi pendukung dan jaringan pendukungnya. Kesalahan dalam mendesain cengkeram dapat menimbulkan distribusi beban yang tidak terkontrolke gigi pendukung dan jaringan pendukungnya. ${ }^{2,3}$

Pada kasus gigitiruan berujung bebas, masalah yang sering timbul adalah ketidakstabilan, yaitu gigitiruan mudah bergeser dan terungkit. Hal ini terjadi karena adanya perbedaan kompresibilitas dukungan antara bagian posterior sadel ujung bebas dengan bagian anteriornya, dan tidak adanya gigi alami di sebelah distal sadel. Perbedaan ini menimbulkan masalah, yaitu gigitiruan berujung bebas selalu tidak stabil. Gigitiruan yang tidak stabil selanjutnya akan menimbulkan masalah terhadap kesehatan jaringan sisa. ${ }^{2-4}$

Tidak adanya gigi alami di sebelah distal sadel yang dapat dipakai sebagai sandaran/retainer juga menyebabkan bagian ujung distal sadel akan lebih bebas bergerak dibandingkan dengan bagian ujung mesial sadel. Ketidakstabilan gigitiruan berujung bebas dapat berupa gigitiruan terungkit pada arah vertikal, yaitu bagian ujung mengungkit pada arah horisontal, rotasi sadel pada poros rotasi sagital dan pergeseran arah anteroposterior. ${ }^{3}$ Untuk mengatasi terungkitnya gigitiruan pada kasus berujung bebas, dapat dilakukan beberapa cara, antara lain dengan meletakkan titik retensi yang jauh ke mesial dari titik/garis fulkrum dan berada di sisi lain. Selain itu, dapat juga membuat mahkota teleskopik pada sisi yang berlawanan dari daerah berujung bebas. ${ }^{2-4}$

Gigitiruan denganmahkota teleskopikmerupakan gigitiruan yang menggunakan mahkota ganda, yang terdiri dari coping dan gigitiruan lepasan di atasnya. Prinsip dari sistem mahkota teleskopik adalah terdiri dari dua elemen,yaitu mahkota internal yang disebut dengan mahkota primerdan mahkota eksternal yang disebut dengan female atau mahkota sekunder. Jadi dengan menggunakan gigitiruan teleskopik, dapat memberikan perlindungan terhadap gigi penyangga, meringankan beban yang diterima gigi penyangga dan memberikan hasil yang lebih estetik. ${ }^{5,6}$

Gigitiruan teleskopik adalah bentuk modifikasi antara ada gigitiruan konvensional dan overdenture dengan keuntungan meningkatkan retensi,dukungan vertikal yang kaku, stabilitas, dan propriosepsi. ${ }^{5,6}$ Gigitiruan mahkota teleskopik adalah gigitiruan lepasan yang mendapatkan dukungan dari gigi penyangga dan lingir sisa atau mukosa. ${ }^{1-5}$ Informasi terbatas mengenai kasus longitudinal pada gigitiruan teleskopik memberikan respon yang baik pada gigi penyangga dan jaringan periodontal. ${ }^{7}$

Pada makalah ini akan dilaporkan dua kasus pembuatan gigitiruan lepasan rangka logam dengan menggunakan mahkota teleskopik pada salah satu giginya yang berfungsi sebagai retainer pada kasus berujung bebas salah satu sisinya.

\section{KASUS DAN PENTALAKSANAAN Kasus 1}

Seorang pasien pria berusia 73 tahun datang ke klinik gigi dengan keluhan gigi 27 terdapat karies luas serta gigitiruanyanglama terasa longgar.Pasien ingin dibuatkan gigitiruan yang baru yang terbuat dari rangka logam. Hasil pemeriksaan menunjukkan gigi 27 non vital, hilangnya gigi 14, 15, 16, 17, dan 26; gigi 28 goyang derajat 1 , serta gigitiruan rangka logam yang lama sudah tidak retentif lagi karena patahnya sebagian mahkota gigi 27 yang merupakan gigi penyangga.

Selanjutnya dilakukan perawatan saluran akar pada gigi 27. Setelah perawatan saluran akar selesai, pada gigi 27 dilakukan preparasi yang menyerupai preparasi pembuatan mahkota penuh, karena gigi 27 direncanakan akan dijadikan gigi penyangga. Selesai preparasi, harus dilakukan pengecekan oklusi dan dievaluasi apakah permukaan oklusal gigi yang dipreparasi sudahmemberikanketebalan yang cukup untuk pembuatan mahkota ganda. Jarak pemukaan oklusal sebaiknya dibuat sekitar $2 \mathrm{~mm}$, sehingga mahkota ganda yang dibuat nantinya tidaklah terlalu

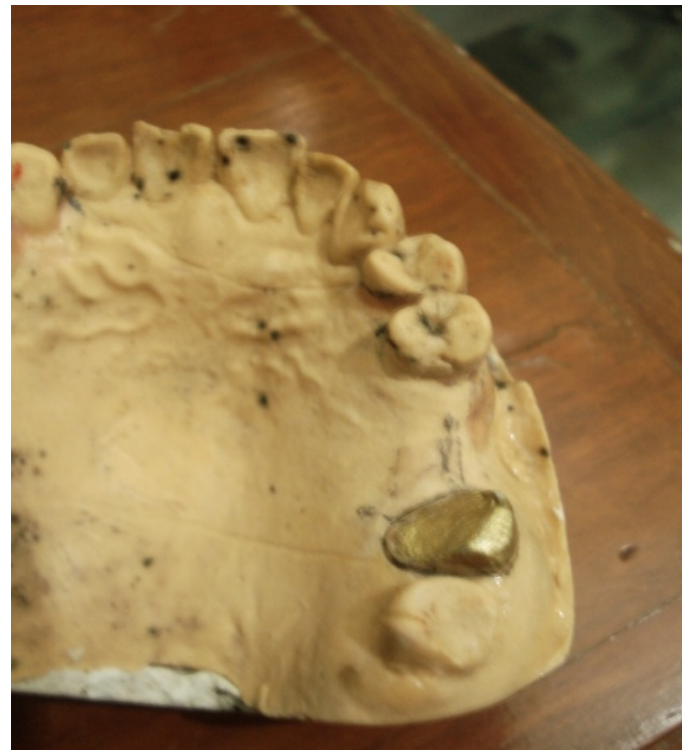

Gambar 1 Model gips rahang atas gigi 27 pasca preparasi persiapan untuk penempatan mahkota primer 
tipis. Selanjutnya dilakukan pencetakan sekunder dengan menggunakan bahan cetak elastomer, lalu model gipsnya (gambar 1) dikirim ke laboratorium untuk pembuatan mahkota primer gigi 27 dan mahkota sekunder yang menyatu dengan gigitiruan rangka logam rahang atasnya (gambar2). Mahkota sekunder dibuat menyerupai mahkota penuh logam dengan pertimbangan gigi 27 akan dapat menerima beban yang besar dan memberikan retensi yang kuat, dan juga karena gigi 27 terletak di posterior sehingga tidak akan mempengaruhi estetik dari gigitiruannya. Bidangmesiodistal darimahkotaprimerdibuatsedikit taper, mengerucut dengan sudut sekitar $8^{\circ}$, sehingga diharapkan diperoleh retensi friksi pada bidang mesiodistal antara mahkota primer dengan mahkota sekunder. Selanjutnya dilakukan proses sementasi mahkota primer pada gigi 27 menggunakan semen resin. Kesehatan jaringan pendukung dipertahankan dengan membersihkan kelebihan semen sehingga pinggiran mahkota primer benar-benar bersih, serta posisi mahkota primer tepat pada gigi penyangga. Selanjutnya dilakukan pemasangan rangka logam gigitiruan rahang atas.

\section{Kasus 2}

Seorang pria datang ke klinik gigi dengan keluhan gigitiruan rahang atas sudah tidak nyaman bila dipakai makan dan gigitiruan rahang bawah longgar.Penderita ingin dibuatkan gigitiruan rangka logam yang baru. Berdasarkan pemeriksaan klinis ditemukan penderita mengalami kehilangan gigi 12 , $15,16,17,22,25,34,35,36,37,46$ (gambar 4). Gigi 44 gangren radiks sehingga dilakukan pencabutan, sedangkan gigi 45 karies profunda bidang distooklusal,lalu dilakukan perawatan pulp capping, dan direstorasi dengan menggunakan komposit. Tahap selanjutnya dilakukan preparasi yang menyerupai pembuatan mahkota penuh pada gigi 45. Gigi 45 dijadikan gigi penyangga menggunakan mahkota teleskopik.Selanjutnya dicetak dengan bahan cetak elastomer pada rahang atas dan rahang bawah untuk memperoleh model kerja. Mahkota primer gigi 45 dibuat terlebih dahulu dan dilakukan sementasi pada gigi 45 (gambar 5), lalu dilakukan pencetakan ulang pada rahang bawah untuk mendapatkan model kerja untuk pembuatan mahkota sekunder yang akan menyatu dengan rangka logam gigitiruan.
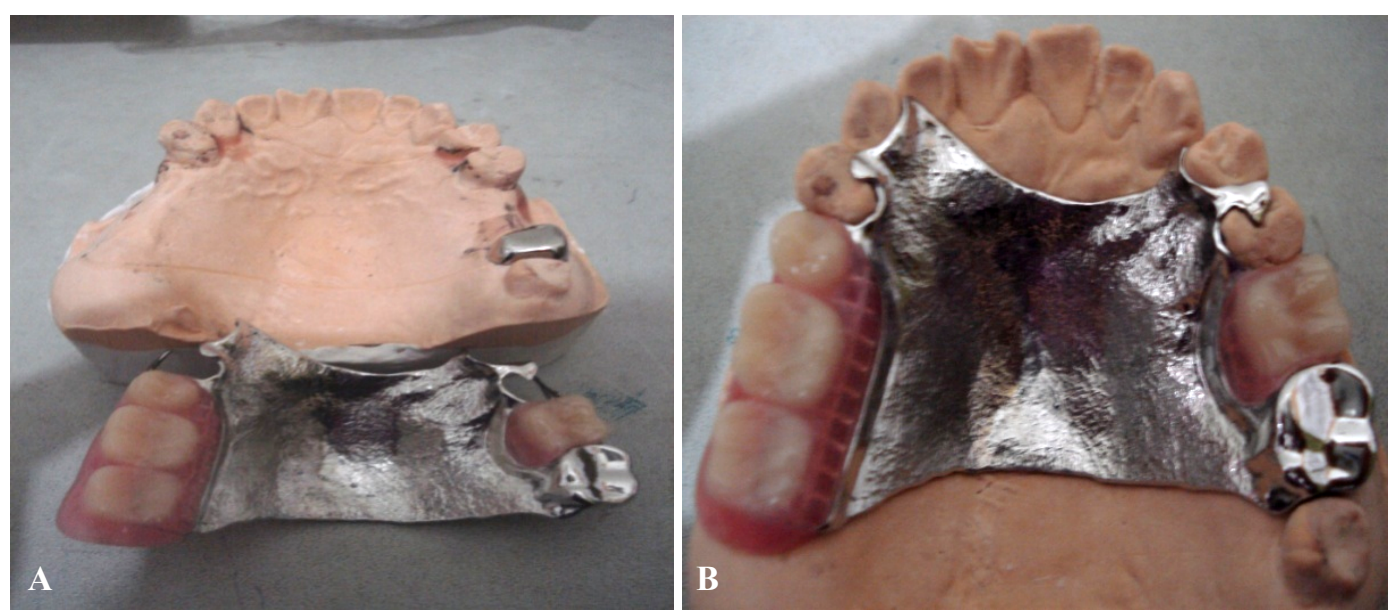

Gambar 2A Mahkota primer pada gigi 27, dan B mahkota sekunder yang dibuat menyatu dengan rangka logam gigitiruan rahang atas
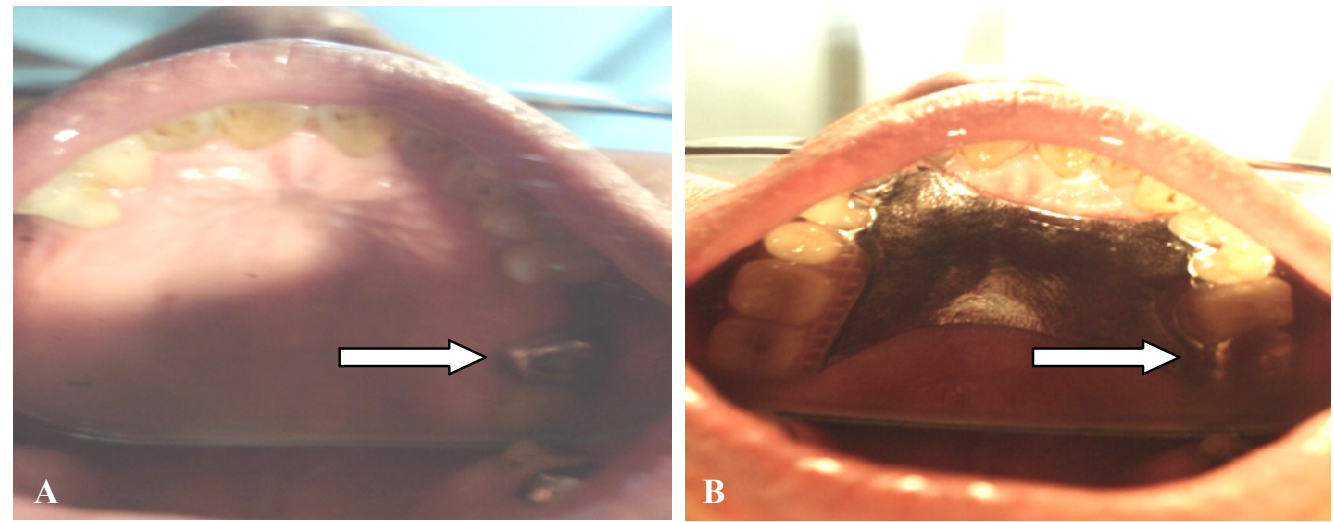

Gambar 3A Kedudukan mahkota primer yang telah dilakukan sementasi pada gigi 27, dan B gigitiruan rangka logam yang telah terpasang pada rahang atas. 
Sebelum pelaksanaan pekerjaan laboratorium pembuatan rangka logam gigitiruan, terlebih dahulu harus diperoleh hubungan oklusi antara rahang atas dan bawah dengan cara pembuatan galengan gigit pada rahang atas dan rahang bawah (gambar 6), disusul mencatat gigitan rahang atas dan bawah. Hal ini dilakukan karena kasus gigitiruan berujung bebas sehingga stop oklusal posterior tidak ada. Selanjutnya model kerja dan catatan gigitan lilin dikirim ke laboratorium guna pembuatan rangka prostesis rahang atas dan mahkota sekunder yang bersatu dengan rangka gigitiruan rahang bawah.

Pada kedua kasus tersebut, dilakukan kontrol 1 minggu, 3 bulan dan 6 bulan setelah pemasangan. Setelah dilakukan evaluasi pasien merasa cukup puas dengan gigitiruan barunya yang stabil (gambar 7).

\section{PEMBAHASAN}

Suatuungkitan ke arah apikal dari basis gigitiruan yangtidakstabil akanmenyebabkan tidak meratanya penyaluran tekanan kunyah. Pada kasus gigitiruan sebagian berujung bebas, tekanan kunyah ke arah apikal akan lebih terkonsentrasi di bagian posterior atau di daerah ujung bebasnya, sehingga menimbulkan tekanan berlebih, yang selanjutnya mengakibatkan resorpsi lingir alveolar yang lebih hebat di tempat tersebut, atau terungkitnya gigi penyagga pada gigi yang paling dekat dengan daerah yang berujung bebas. ${ }^{2-4}$

Prinsip objektif perawatan adalah menyediakan lingkungan yang sesuai untuk konstruksi fungsional, kenyamanan, dan prostesis estetik. Mempertahankan gigi penyangga yang kurang baik akibat karies yang luas, meningkatkan propriosepsi, dan meningkatkan retensi, dukungan vertikal yang kaku, dan stabilisasi pada prostesis, merupakan keuntungan dari desain prostesis mahkota teleskopik yang memperlihatkan pilihan yang baikuntukpenggantian pada kehilangan gigi dibanding dengan pemakaian gigitiruan lepasan yang hanya mengandalkan retainer yang berbentuk cengkeram. ${ }^{7,8}$

Devitalisasi gigi penyangga untuk pembuatan prostesis mahkota teleskopik dapat dilakukan hanya bila gigi tersebut cukup tebal pada lapisan dentin sekunder yang menutupi pulpa dan tampak secara
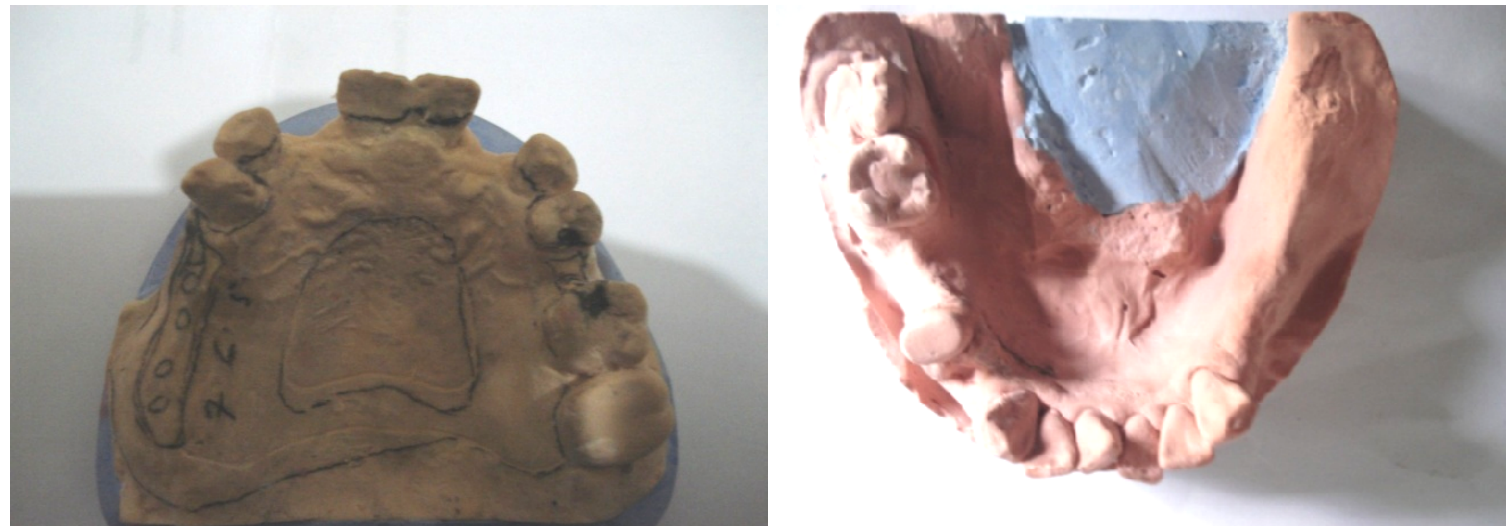

Gambar 4 Model kerja awal; A rahang atas, dan B rahang bawah (terlihat gigi 45 yang telah dilakukan preparasi guna persiapan untuk pembuatan mahkota teleskopik).
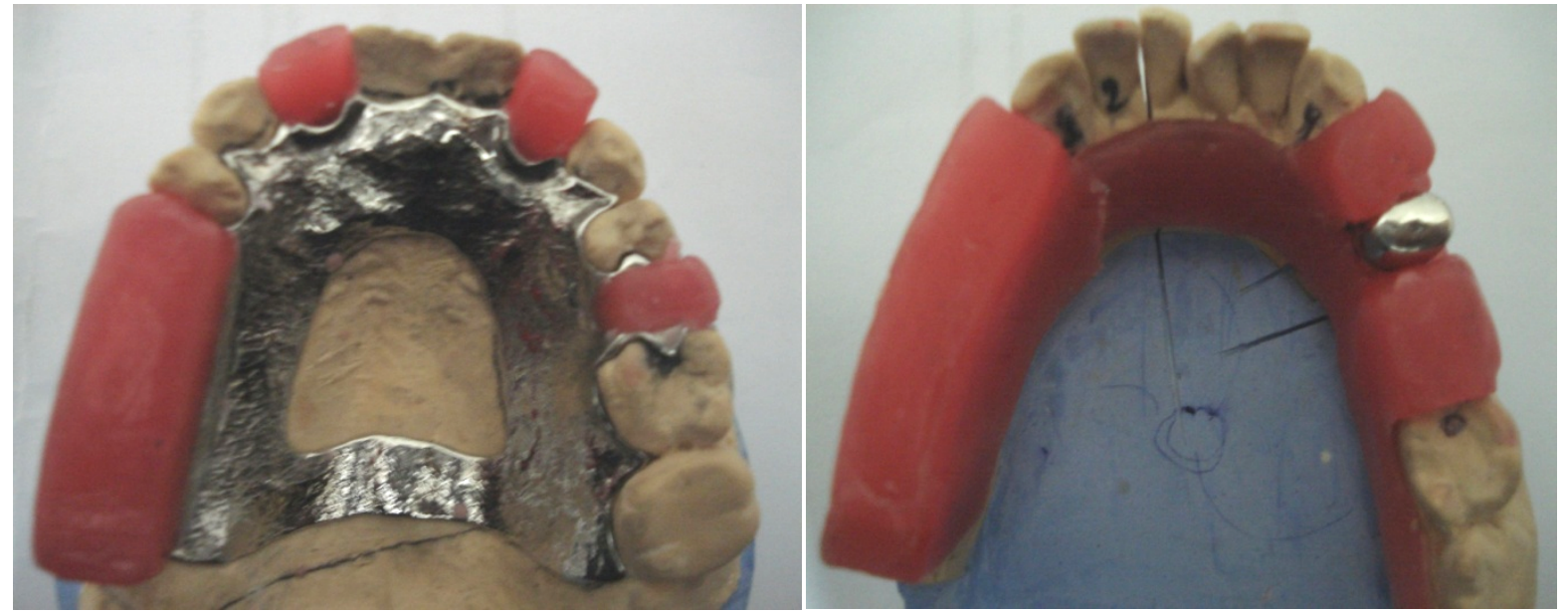

Gambar 5 Rangka logam gigitiruan dan tanggul gigitan untuk mencari hubungan oklusi rahang atas dan rahang bawah 

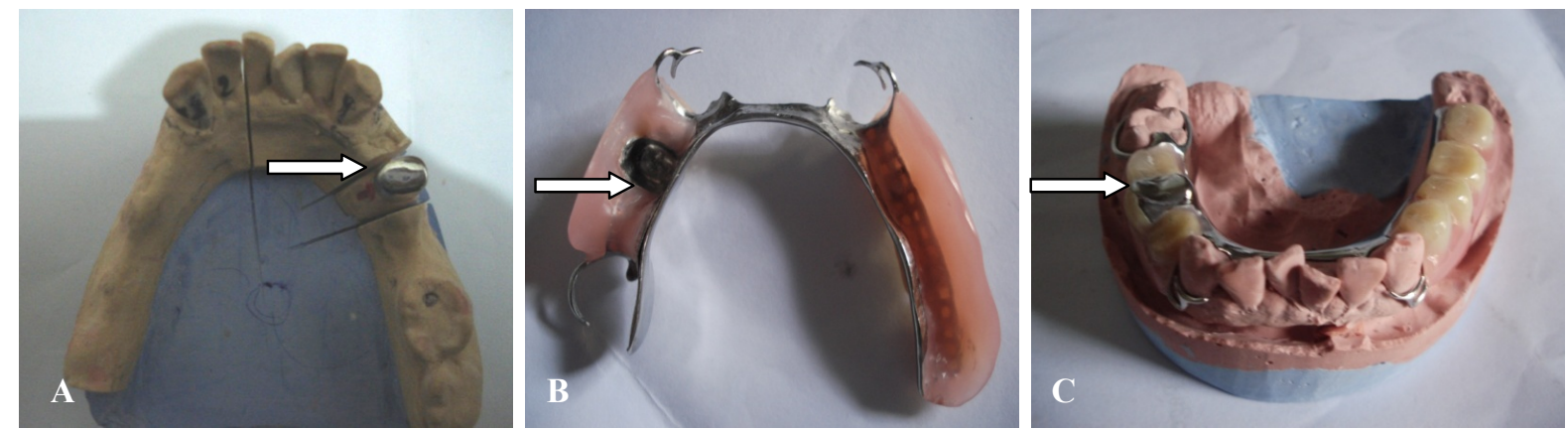

Gambar 6A Mahkota primer pada gigi 45 (tanda panah putih), B mahkota sekunder yang menyatu dengan rangka logam gigitiruan rahang bawah, dan $\mathbf{C}$ terlihat pada bagian bukal dilapisi dengan bahan akrilik putih guna memberikan estetis yang baik.
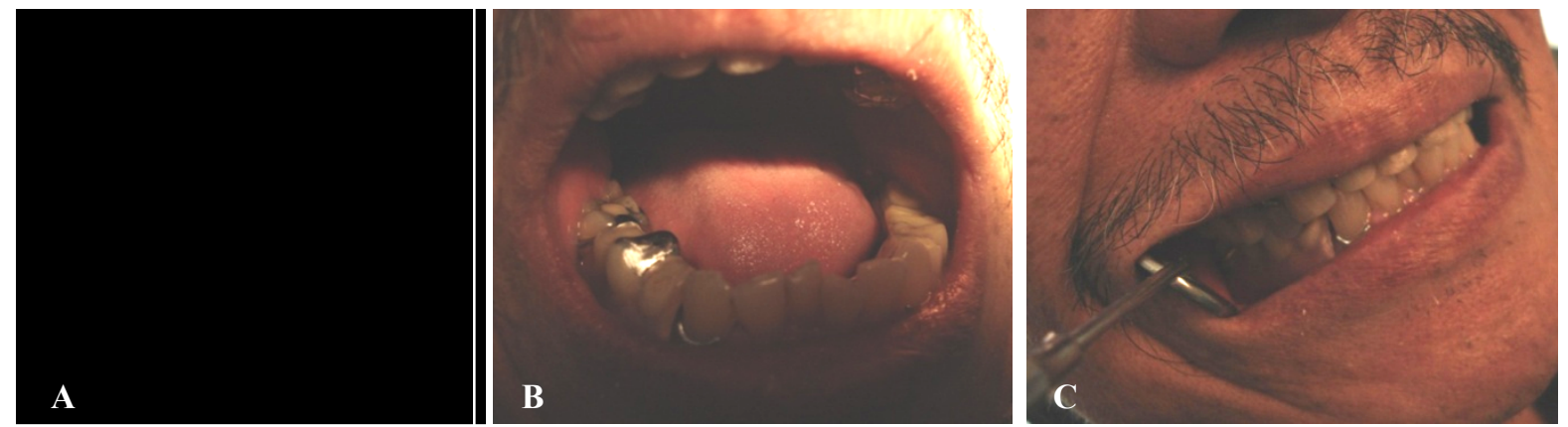

Gambar 7A, B. C Kedudukan mahkota teleskopik pada intra oral (tanda panah putih)

klinis. Yelisove mengindikasikan untuk melakukan ekstirpasi vital pada struktur gigi yang cukup yang dapat menghasilkan peningkatan perbandingan antara mahkota dan akar. ${ }^{7}$

Mahkota teleskopik berfungsi membebaskan stres horisontal dan memberikan hasil yang baik juga pada perawatan traumatik sekunder. Selain itu prostesis mahkota teleskopik memberikan beberapa keuntungan.Penggunaan prostesis ini dapat merawat gigi penyangga yang lemah serta banyak kehilangan tulang alveolar, gaya paralel pada lengan jembatan yang panjang dapat memberikan kesehatan pada jaringan periodontal,meningkatkan rasio antara akarmahkota dan dengan bentuk coping yang taper meminimalkan gayaungkit dari soket,meningkatkan estetik gigitiruan sebagian lepasan dibandingkanjika menggunakan cengkeram, dan selanjutnya prostesis ini memungkinkan kemudahan jika gigi penyangga dicabut. $^{7-9}$
Beberapa penulis mengatakan bahwa terdapat beberapa keuntungan prostesis teleskopik, yaitu tekanan yang diterima sumbu aksial gigi penyangga langsung diteruskan ke penyangga dan menstimulasi jaringan periodontal dan tulang alveolar di bawahnya. Selain itu, adanya coping pada gigi penyangga yang berfungsi sebagai retainer yang diperoleh secara friksi memberikan reaksi yang positif, yaitu dapat meminimalkan tilting dari gigi penyangga. ${ }^{7,9}$

Penggunaan mahkota teleskopik pada salah satu gigi penyangga gigitiruan sebagian lepasan berujung bebas disimpulkan dapat memberi kondisi yang sesuai untuk kontruksi fungsional, kenyamanan, meningkatkan retensi, mencegah gigi penyangga terungkit, memberi dukungan vertikal yang kaku, stabilitas serta estetis yang memuaskan, sehingga menjadi salah satu pilihan untuk kehilangan gigi dibandingkan dengan pemakaian gigitiruan yang hanya mengandalkan cangkolan sebagai retainer.

\section{DAFTAR PUSTAKA}

1. Neill DJ, Walter D.J. Buku pintar: Geligi tiruan sebagian lepasan. Edisi 2. Jakarta: EGC; 1992. hal. 1, 28-31.

2. Ardan R. Disain gigi tiruan sebagian lepasan frame: kasus berujung bebas. Bandung: Makalah seminar nasional Peril IKG 25-26 Mei 2007.

3. Sutanto D. Distribusi beban kunyah cangkolan RPI dan RPL pada kasus gigi tiruan berujung bebas rahang bawah dengan metoda fotoelastik [tesis]. Bandung: Program pendidikan Dokter Gigi Spesialis Prosthodontik, Fakultas Kedokteran Gigi Universitas Padjajaran; 2007.

4. Gurbulak, Deger S. Photoelastic stress analysis of distal exstension removable partial telescopic denture with different conical crown. Available: http://sagens.erciyes.edu.tr//dergi/2009_2/aysegulgurbulak.pdf. Diakses 25 September 2010. 
5. Dabrowa T, Paek H, Napadlek P. 8-year clinical observation of telescopic anchors aplied in removable denturescase report. Dent Med Probl 2007; 44(4): 521-5.

6. Barclay CW. Fixed removable prosthodontics. New York: Churchill Livingstone; 2001. p.137-8.

7. Lin HG, Cheng TC. Periodontal and prosthetic therapy in severely advanced periodontitis by the use of the crown sleeve coping telescope denture: A longitudinal case report. Aust Dent J 1997; 42(3): 169-74.

8. Wang $\mathrm{CH}$, Lee HE, Igarashi Y. Conical crown telescope, cylindrical slide, dovetail slide beyeler spang. Kaoshing J Med Sci 2005; 21(1). Available from http://74.146/search/cache. Diakses tanggal 15 Juni 2009.

9. Telescopic denture and bridge. Available from: http://images.google.co.id/imgres?imgurl=http://www. hannoverdental.eu/nofi/Images/APP_82_962892255_MOO_508621.jpg\&imgrefurl. Diakses tanggal 15 Juni 2009. 